TURIZAM

Volume 21, Issue 2 102-110 (2017)

ORIGINAL

SCIENTIFIC PAPER

\title{
The influence of the local residents attitudes on the consumption of food products in the function of the development of gastronomic tourism
}

\author{
Nikola Vuksanović ${ }^{A}$, Dragan Tešanović ${ }^{B}$, Milijanko Portić ${ }^{B}$, Predrag Tošićc \\ Received: Jun 2017 | Accepted: Jun 2017 \\ DOI: 10.18421/TRZ21.02-04
}

\begin{abstract}
The purpose of the study is to examine the influence of attitudes of the local residents on the consumption offood products. The survey included a sample of 332 respondents who visited 15 events that take place in the territory of Novi Sad. The findings of this study point to the importance of attitudes of the local residents as an important component of the development of gastronomic tourism. The study included examining the differences between the socio demographic characteristics of the local residents in relation to consumption of food products. The differences were examined using the T-test for independent samples. The results show that there are differences between gender, age groups and levels of education, but not for monthly incomes in relation to consumption of food products. This study allows the economic and local sectors to better understand the importance of attitudes of the local residents and consumption of food products, as part of gastronomic tourism, and how to improve the acceptability among visitors.
\end{abstract}

Key words: gastronomic tourisam, consumption of food products, local residents attitudes, Novi Sad

\section{Introduction}

In tourist destinations, the local residents is an important interest group because, the future, that is, the success of the product itself depends on their acceptance or refusal of tourism development and the creation of a tourist product. The local residents can have both positive and negative attitudes towards the development of tourism, which depends mostly on inclusion in tourism, but also on the tradition of tourism destination development.

A Department of Hospitality, Higher education school for management and business communication, Mitropolita Stratimirovića 110, 21205 Sremski Karlovci, Serbia; corresponding author: vuksanovicnikola85@gmail.com

B Department of Geography, Tourism and Hotel Management, Faculty of Science, University of Novi Sad, Trg Dositeja Obradovića 3, 21000 Novi Sad, Serbia

c University of Business Studies, Faculty of Tourism and Hotel Management, Banja Luka, Republika Srpska 
The main subject of this paper is to examine the attitudes of the local residents at the event. Can the local residents attitudes and consumption of food products play an important role in the development of gastronomic tourism? This paper reports on research related to the contribution of local residents attitudes, consumption of food products and events in the function of developing gastronomic tourism.

The number of food events held worldwide is increasing as a result of the growing interest in food tourism, which has become largely recognized as a form of recreational and tourist attraction. Previous research has identified that regional food manifestations can play an important role not only in economic development (du Rand, et al., 2003; du Rand, Heath, 2006) but also in the development of regional tourism, adding value to already existing products (Quan, Wang, 2004). In addition, food manifestations are used as the promotion of local facilities and differ from manifestations of metropolitan communities (Cela, et al., 2007; Sharples, 2008; Lee, Arcodia, 2011; Kalenjuk, et al., 2012a; Kalenjuk, et al., 2012b).

\section{Literature review}

In the subject literature, the group of authors (Cecil, et al., 2010) point out that the local residents is a very important participant in the development of tourism destinations, and is interested in its development, because they are aware that using resources and poor management decisions can result in the destruction of existing values in their environment. The quality of life of the residents in the destination must not be disturbed because its destruction and distortion bring the loss of local residents, which should be one of the holders of economic development. The contentment with life in the destination is higher and it grows during the stage of maturity of tourism development because the inhabitants feel the consequences of tourism development materially, but when tourism development begins to decline, the quality of life in the destination decreases.

According to research and counseling agency (Enteleca Research and Consultancy, 2000), local food and beverages are material goods produced in the local area. In addition, local foods with a local identity, including locally produced and regionally branded products such as cheeses, meat, and others, are included in local food and beverages. Boniface (Boniface, 2003) offers a more complicated definition of local food. He suggested that this term includes food and beverages that originate from places that are not too far from the place of consumption, or that it is not necessary to use a refrigerator to keep the food fresh and can be consumed shortly after growth or production.

Food as the identity of a destination can attract a wide range of tourists because local cuisine can enliven cultural experiences, cultural identity, communication and status (Chang, et al., 2011). The unique identity of a particular food and food culture offers a recognizable image of each region, which can be efficiently used to differentiate destinations.

In the subject literature (Furst, et al., 1996; Khan, 1981; Randall, Sanjur, 1981) sociological and demographic factors are recognized as important variables in explaining variations in food consumption in different contexts.

The choices of food refer to "a set of conscious and unconscious decisions of a person the time of purchase, consumption or any moment between" (Herne, 1995; Kalenjuk, et al., 2015). In the overall form, food choices create consumer demand for suppliers in the food system who produce, process and distribute food (Sobal, et al., 1998). The choice of food also plays an important role in the symbolic, economic and social aspects of life, as it is a way to express preferences, identities and cultural meanings (Sobal, et al., 2006). Consumption of food refers to the 
amount of food actually consumed by an individual (Kissileff, Van Italie, 1982). Researchers in the field of food consumption agree that these factors can be classified into three broad categories: food, environment and individual (Gains, 1994; Meiselman, et al., 1999; Randall, Sanjur, 1981; Shepherd, Raats, 1996).

\section{Methodology}

The survey was conducted in the territory of Novi Sad in 2016. In the survey, the target population is made up of residents of the city of Novi Sad, who live in Novi Sad. The research was conducted at tourist events that take place in Novi Sad. The events at which the research was conducted are:

- Days of Brazil (August),

- Young Wine Days - Portugizer (November),

- Enter - Wine Festival (July),

- Kulinijada (July),

- Event -Business Exit (March),

- International Tourism Fair (September),

- International Wine Festival - Winexpo (November),

- International Wine Festival - Interfest (July),

- German "pretzel ball" - Deutscher brezerball (February),

- Novi Sad Autumn (October),

- From Christmas to Christmas (December),

- Competition in cooking fish soup (July),

- Easter Street (April),

- Honey Festival (September),

- Čenej in May (May).

The sampling method is a simple random sample method. The survey was conducted through trained interviewers, where each visitor who attended the event was a member of a set of random samples. The task of interviewers was to personally interview visitors. Since the interview was conducted through the paper and pencil interviewing (PAPI) (Lavrakas, 2008), the ability of the interviewers to explain the questions in the survey form if required by the respondents was essential. A total of 500 questionnaires were distributed and 332 (63\%) useful questionnaires were received.

For the purposes of this study, and based on previous research (Jalis, et al., 2009), a questionnaire was used to examine the attitudes of the local residents towards the consumption of food products. The questionnaire was modified and adapted for this research. An interview was organized with tourism representatives (academic experts, hotel employees and representatives of tourist organizations) in which experts gave their comments and suggestions which attributes should be taken into account when creating a scale for examining the attitudes of the local residents. Based on qualitative research, it was found that certain questions - items are not appropriate for the purposes of the research. Finally, a total of 14 attributes (questions, items) were identified, which were further used in the scale for examining the attitudes of the local residents.

The questionnaire consists of three parts. The first part of the questionnaire is the respondent's consent to fill out the questionnaire. Filling out a questionnaire is anonymous. The second part refers to the demographic and socio-economic characteristics of the respondents: 
gender, age, level of education and monthly income. The third part of the questionnaire refers to the examination of attitudes of the local residents towards the consumption of food products (Table 5), which contains 14 items. In the questionnaire, the concept of collecting and processing attitudes is defined as the degree to which the perception of the attributes shows the attitude and consumption of food products at the manifestation. Answers to the questionnaire were measured based on the Likert scale, 1- strongly disagree, 2 - mostly disagree, 3-neutral, 4 - generally agree, and 5 - absolutely agree.

In order to check the differences between the socio-demographic characteristics of visitors in the consumption of food products, a T-test for independent samples was conducted. The dependent variable is the consumption of food products and the examined factors are the socio-demographic characteristics of visitors: gender (2 levels), age (5 levels), education (6 levels) and monthly income (3 levels).

\section{Results}

\section{Characteristics of respondents}

The study covered 332 respondents in the area of Novi Sad. Of the total number of respondents, $52.5 \%$ were male and $47.5 \%$ female (Table 1 ).

Table 1. Gender structure of the sample

\begin{tabular}{|c|c|}
\hline Gender & Novi Sad \\
\hline Male & 176 \\
\hline Female & 158 \\
\hline
\end{tabular}

Table 2 shows the age structure of the sample by cities. Almost half of the respondents consist of younger respondents aged 18 to 30 years. As can be seen, the majority of respondents are in the category between 18 and 30 years who visited the manifestations. The next category consists of respondents aged 31 to 40 who attended the manifestations while the smallest number of respondents was in the category between 41 to 50 years of age.

Table 2. Age structure of the sample

\begin{tabular}{|c|c|}
\hline Age & Novi Sad \\
\hline $18-30$ & 108 \\
\hline $31-40$ & 66 \\
\hline $41-50$ & 48 \\
\hline $51-60$ & 50 \\
\hline Over 60 years & 58 \\
\hline
\end{tabular}

Table 3 shows the sample structure by level of education. The largest number of respondents have completed secondary school $(\mathrm{N}=80)$. Approximately the same number of respondents have completed college $(\mathrm{N}=75)$ and faculty /bachelor $(\mathrm{N}=70)$. A slightly lower number of respondents have completed primary school $(\mathrm{N}=48)$, while slightly lower number of respondents have completed master $(\mathrm{N}=4 \mathrm{O})$ and the smallest number of respondents have completed doctoral studies $(\mathrm{N}=18)$. 
Table 3. Sample structure by level of education

\begin{tabular}{|c|c|}
\hline Education & Novi Sad \\
\hline Primary school & 48 \\
\hline Secondary school & 80 \\
\hline College & 75 \\
\hline Faculty-bachelor & 70 \\
\hline Faculty- master & 40 \\
\hline Doctoral studies & 18 \\
\hline
\end{tabular}

Table 4 shows the sample structure in terms of the average monthly income of respondents who visited the manifestations. Most respondents $(\mathrm{N}=165)$ estimated that they had average household income, while fewer respondents estimated their incomes as above average $(\mathrm{N}$ = 93). The smallest number of respondents estimated that they have that they have below average household income $(\mathrm{N}=69)$.

Table 4. Sample structure according to monthly household income

\begin{tabular}{|c|c|}
\hline Income & Novi Sad \\
\hline Below average & 69 \\
\hline Average & 165 \\
\hline Above average & 93 \\
\hline
\end{tabular}

\section{Descriptive analysis}

Answers to questions related to food consumption are shown in Table 5, whereby the response format to items is designed to encourage respondents to assess the local residents attitude towards consumption of food products. At the same time, it shows means and standard deviations of the scale items for examining the attitudes of the local residents towards the food consumption. Most respondents agree that most foodstuffs stimulate appetite $(M=4.49$, item 1$)$. It is not surprising that they enjoyed most food products $(M=4.56$, item 2$)$ and that they spent a lot of money visiting the manifestation $(M=4.06$, item 3$)$. At the same time, partial disagreement or neutral attitude can be noticed in the assessment of item $4(M=2.74)$. In fact, visitors did not agree with the view that they just tried food products. What can be concluded based on the result is that visitors have tried and get interested in most food products during the visit, regardless of whether they have already tried the product before. This is probably explained by the high level of disagreement with the item "I only consumed food products that I knew well" $(\mathrm{M}=2.19$, item 5). Interestingly, (Table 5) despite having tried most of the food products, visitors were not quite sure about whether the taste, texture and appearance of food products were uniform, regardless of the place of manifestation $(M=2.44$, item 6$)$. This fits well with their disagreement with the item "I only consumed local food products" $(M=3.41$, item 7$)$.

It is noted that visitors mostly assessed their experiences regarding food products positively (items 8 and 9), that is, they enjoyed the consumption of food products and local gastronomic specialties. Respondents stated that they enjoyed and experienced the traditional way of preparing food products $(M=4.38$, item 10). Most respondents agreed relatively that they tried some ways of traditional food consumption $(M=3.77$, item 11 and $M=3.90$, item 12) and learned about the tradition and the food culture at cultural events during the visit $(M=3.15$, 
item 13). What can be concluded with the above arguments, the respondents expressed certain agreement that they had learned enough about the food culture $(M=3.83$, item 14).

Table 5. Descriptive indicators of the scale for examining the attitudes of the local residents towards the consumption of food products

\begin{tabular}{|c|c|c|}
\hline \multirow[t]{2}{*}{ Items } & \multicolumn{2}{|c|}{ Novi Sad } \\
\hline & M & SD \\
\hline 1. Most food products stimulate appetite & 4.49 & .752 \\
\hline 2. I enjoyed most food products during the event & 4.56 & .70 \\
\hline 3. I spent a lot of money on food products during a visit to the event & 4.06 & 1.04 \\
\hline 4. I just tried the food products at the event & 2.74 & 1.27 \\
\hline 5. I consumed exclusively food products that I knew very well & 2.19 & 1.30 \\
\hline $\begin{array}{l}\text { 6. The taste, texture and appearance of most food products are uniformed, regardless of } \\
\text { the manifestation }\end{array}$ & 2.44 & 1.15 \\
\hline 7. I only consumed local food products & 3.41 & 1.31 \\
\hline 8. The experience of visiting the event is delighting me & 4.14 & .98 \\
\hline 9. I enjoyed eating food products in large quantities & 4.14 & 1.01 \\
\hline 10. I enjoyed eating traditional food products & 4.38 & .80 \\
\hline 11. I experienced several traditional methods of preparing food products & 3.77 & 1.24 \\
\hline 12. During my visit, I tried most of the traditional ways of consuming food products & 3.90 & 1.13 \\
\hline 13. I have mostly learned about the tradition and culture of food at cultural events & 3.15 & 1.31 \\
\hline 14. During my visit, I have learned enough about the food culture & 3.83 & 1.12 \\
\hline
\end{tabular}

Table 6 shows the descriptive analysis of the applied scale. Based on the values of multivariate skewness and kurtosis, it can be concluded that the answers of the respondents to the scale of the consumption of food products do not deviate significantly from normal distribution. In this survey, the reliability coefficients expressed in terms of Kombah alfa are .81 (Table 6).

Table 6. Descriptive analysis of the scale

\begin{tabular}{|l|c|c|c|c|c|c|c|c|}
\hline Scale & Min. & Max. & M & SD & Skew. & Kurt. & K-C & $\alpha$ \\
\hline $\begin{array}{l}\text { Consumption of } \\
\text { food products }\end{array}$ & 18.00 & 55.00 & 39.23 & 7.28 & -.259 & -.315 & $0.268^{*}$ & 0.81 \\
\hline
\end{tabular}

Note. ${ }^{*} P<0.1$ : Min. - minimum score; Max. - maximum score; $M$ - arithmetic mean; SD - standard deviation; Skew. - skewness; Kurt. - kurtosis; K-S - Kolmogorov-Smirnov test; A - Reliability of the scale measured by internal consistency

\section{Differences in socio-demographic characteristics of respondents}

In order to check the gender differences between respondents in consumption of food products, $\mathrm{T}$ test for independent samples was applied with factors: gender (male/female) and consumption of food products. The results show that there is a statistically significant difference between genders (T-test 1.83; $\mathrm{p}<0.05$ ). These results show that men are significantly different from women when it comes to consumption of food products, in the sense that they have a more positive attitude towards consumption during a visit to the event.

The T-test results for the independent samples show that there is a statistically significant difference between age groups. $\mathrm{T}$ test value is 3.32 , and is statistically significant $(\mathrm{p}=0.00)$. 
The results show that there is a significant difference between respondents belonging to the age group between 18 and 30 years and respondents belonging to the category between 51 and 60 years $(\mathrm{p}<0.05)$. Furthermore, it has been shown that there is a difference between respondents aged $31-40$ and visitors aged 41-5o $(\mathrm{p}<\mathrm{O} .02)$, as well as in relation to visitors who are $51-60$ years old $(\mathrm{p}<\mathrm{o.oo})$.

In order to check the differences in education among respondents in consumption of food products, the $\mathrm{T}$ test for independent samples was applied with factors: education (6 levels) and consumption of food products. The results show that there is a statistically significant difference between the education groups (T-test 2.86; $\mathrm{p}<0.02$ ). It has been shown that there is a significant difference between respondents with completed secondary school and faculty- bachelor $(\mathrm{p}<0.05)$, respondents with completed secondary school and visitors with faculty - master $(\mathrm{p}<0.01)$ and respondents with completed secondary school and respondents with completed doctoral studies $(\mathrm{p}<\mathrm{0} .00)$.

The T-test results for independent samples show that there is no statistically significant difference between groups of monthly incomes in consumption of food products. The $T$ test value is 0.89 , and is not statistically significant $(\mathrm{p}=0.25)$.

\section{Discussion}

The obtained results indicate that there are differences between variables: gender, age and level of education, but not in the variable of monthly income for consumption of food products. Findings indicate that men differ significantly from women when it comes to consumption of food products. Findings show that there is a difference between the age variable in the consumption of food products. In particular, respondents belonging to the older category have a more positive attitude towards the consumption of food products. Possible differences between visitor groups in the variable of level of education, where visitors with a higher level of education have a more positive attitude towards the consumption of food products, can be explained by the fact that they were more willing to try more products than other groups of respondents. It can be assumed that respondents with a lower level of education are less concerned about health than respondents with a higher level of education. Findings point out, but only the tendency, that visitors with below-average incomes in a somewhat more pronounced degree positively assess the consumption of food products compared to other groups (above-average and average incomes).

Based on the results and discussion, it is noted that respecting the differences between groups of respondents based on their socio-demographic characteristics is important for future research and testing when it comes to the attitudes of the local residents and the consumption of food products at manifestations.

According to the author's findings, similar studies have not been carried out so far in Novi Sad (Vuksanović, et al., 2016; Vuksanović, et al., 2017), and this paper gives a new insight into the importance of attitudes of the local residents and the consumption of food products as part of gastronomic tourism and how to improve acceptability among visitors.

The obtained results indicate that the local residents mostly positively assessed their experiences regarding food products, that is, they enjoyed the consumption of food products and local gastronomic specialties.

Attitudes are also influenced by the advantages of tourist development, for example, an increase in the income of the population (ensuring economic independence and stability of the region), ensuring the construction of communal infrastructure, encouraging small entrepre- 
neurship, creating a recognizable tourism offer of a destination, branding autochthonous offer and encouraging the return of the population, but also the disadvantages that such development brings, emigration of the population, overcoming of the accepting potential, destruction of natural and cultural resources, destruction of autochthonousness, inability of year-round employment in destinations that seasonally operate.

When planning tourist destination development, destination management must take into account the wishes, proposals and good initiatives of the local residents, because only in this way it will be possible a more organize and better quality development of tourism of the destination, and it also will reduce the impact of deficiencies and negative attitudes of the population towards tourism.

\section{Conclusion}

Achieving the best possible tourist development of destinations, planning must include the local residents because what is a product to tourists that is offered on the tourist market, this is a living space for the local residents in which everyday life takes place.

The population will be satisfied with the tourist development if it provides certain advantages such as, for example, possibility of employment, improvement in infrastructure, creation of conditions for small entrepreneurship, and above all, if the quality of life in the tourist destination is not disturbed.

The development of the tourist destination will be successful if all the factors important for the improvement of the development are combined, and these are actors of offer, tourists, the environment and the local residents that is central in this paper. By joint integration, it is possible to create a competitive tourism destination in a demanding tourism market.

\section{Acknowledgment}

This study resulted as a part of project of Provincial Secretariat for Higher Education and Scientific Research, no. 142-451-2669 / 2017-01 / 02 (Agricultural, food and gastronomic products in the function of development of Vojvodina tourism directed towards authentic and safe food).

\section{References}

Boniface, P. 2003. Tasting tourism: travelling for food and drink, Ashgate Publishing Ltd.

Cecil, A. K., Fu, Y., Wang, S., Avgoustis, S. 2010. Cultural tourism and quality of life: Results of a longitudinal study. European Journal of Tourism Research, 3, 1, 54-66.

Cela, A., Knowles-Lankford, J., Lankford, S. 2007. Local food festivals in Northeast Iowa communities: a visitor and economic impact study. Managing Leisure, 12, 171-186.

Chang, R. C., Kivela, J., Mak, A. H. 2010. Food preferences of Chinese tourist. Annals of Tourism Research, 37, 4, 989-1011.

Du Rand, G. E., Heath, E. 2006. Towards a framework for food tourism as an element of destination marketing. Current Issues in Tourism, 9, 3, 206-234.

du Rand, G.E., Heath, E., Alberts, N. 2003. The role of local and regional food in destination marketing: A South African situation analysis. Journal of Travel E Tourism Marketing, 14, 3/4, 97-112. 
Enteleca Research Consultancy, 200o. Tourist's Attitudes Towards Regional and Local Food, The Ministry of Agriculture, Fisheries and Food, and The Countryside Agency by Enteleca Research and Consultancy Ltd.

Furst, T., Connors, M., Bisogni, C. A., Sobal, J., Falk, L. W. 1996. Food choice: a conceptual model of the process. Appetite, 26, 3, 247-266.

Gains, N. 1994. The repertory grid approach. In Measurement of food preferences, 51-76. Springer US.

Herne, S. 1995. Research on food choice and nutritional status in elderly people: a review. British Food Journal, 97, 9, 12-29.

Jalis, M. H., Zahari, M. S., Zulkifly, M. I., Othman, Z. 2009. Malaysian gastronomic tourism products: Assessing the level of their acceptance among the western tourists. South Asian Journal of Tourism and Heritage, 2, 1, 31-44.

Kalenjuk, B., Čomić, Đ., Tešanović, D., Armenski, T., Škrinjar, M. 2012a. Tourists manifestations in the development of culinary tourism in Vojvodina. Tourism \& Hospitality Management, Conference Proceedings, 5-6 Maj, Opatija, Croatia, 316-322.

Kalenjuk, B., Tešanović, D., Gagić, S., Erdeji, I., Banjac, M. 2015. Offer of authentic food as a condition for gastronomic tourism development. The European Journal of Applied Economics 12/2, 27-34.

Kalenjuk, B., Tešanović, D., Gagić, S., Vuksanović, N., Škrinjar, M. 2012b. Tourism manifestation in the culinary tourism in Banat (Vojvodina, Serbia). Geographica Timisiensis 2, 45-52.

Khan, M. 1981. Evaluation of food selection patterns and preferences. CRC Critical Reviews in Food Science and Nutrition, 15, 129-153.

Kissileff, H. R., Van Itallie, T. B. 1982. Physiology of the control of food intake. Annual review of nutrition, 2, 1, 371-418.

Lee, I., Arcodia, C. 2011. The Role of Regional Food Festivals for Destination Branding. International Journal of Tourism Research, 13, 4, 355-367.

Lavrakas, P. J. 2008. Encyclopedia of Survey Research Methods: AM (Vol. 1). Sage.

Meiselman, H. L., Mastroianni, G., Buller, M., Edwards, J. 1998. Longitudinal measurement of three eating behavior scales during a period of change. Food quality and preference, 10, 1, 1-8.

Quan, S., Wang, N. 2004. Towards a structural model of the tourist experience: An illustration from food experiences in tourism. Tourism management, 25, 3, 297-305.

Randall, E., Sanjur, D. 1981. Food preferences-their conceptualization and relationship to consumptiont. Ecology of food and nutrition, 11, 3, 151-161.

Sharples, L. 2008. Apples, cider and celebration. In book: Food and Wine Festivals and Events Around the World, Hall CM, Sharples L (eds). Butterworth-Heinemann: Oxford; 134-145.

Shepherd, R., Raats, M. M. 1996. Attitudes and beliefs in food habits. In Food choice, acceptance and consumption, Springer US, 346-364.

Sobal, J., Bisogni, C. A., Devine, C. M., Jastran, M. 2006. A conceptual model of the food choice process over the life course. Frontiers in Nutritional Science, 3, 1.

Sobal, J., Khan, L. K., Bisogni, C. 1998. A conceptual model of the food and nutrition system. Social Science \& Medicine, 47, 7, 853-863.

Vuksanović, N., Tešanović, D., Kalenjuk, B. 2016. Lokalna gastronomija kao sredstvo marketinga destinacije - primer Republike Srbije. Marketing, 47, 4, 305 - 311.

Vuksanović, N., Tešanović, D., Kalenjuk, B., Portić, M., Knežević, M. 2017. Socio - demographic characteristics as determinants of differences in perception of local gastronomy. Economics of Agriculture, 64, 1, 179-194. 